
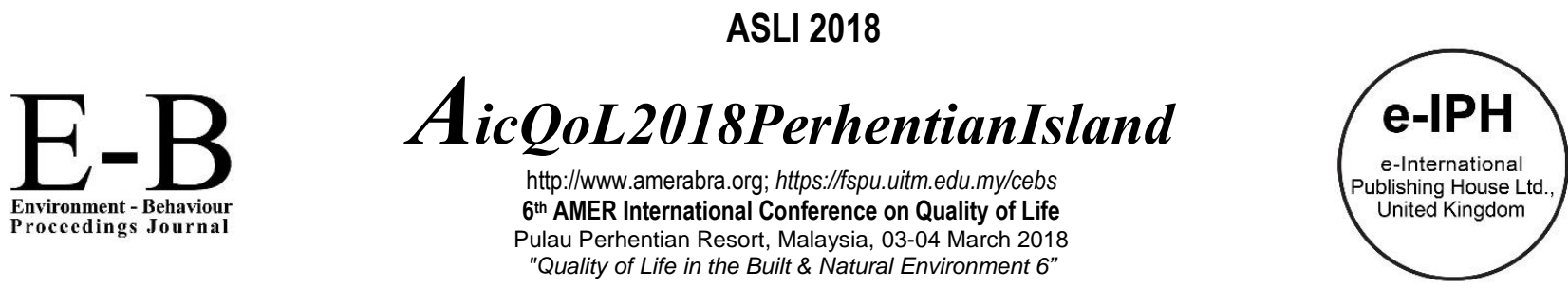

\title{
Theoretical Framework for Trees Management in Campus Landscape Design
}

\author{
Ramly Hasan¹, Nor Diana Aziz¹ Abdul Hadi Nawawi ${ }^{1}$ Ghazali Mohd Amin² \\ ${ }^{1}$ Centre of Post Graduate Studies, ${ }^{2}$ Centre of Studies for Building Surveying, \\ Faculty of Architecture,Planning and Surveying, \\ Universiti Teknologi MARA,40450 ShahAlam,Selangor \\ ramlyhasan80@yahoo.com \\ Tel: +60195263622
}

\begin{abstract}
Good tree management is the key basis for greener campus of the future. Lacking in tree management in term of knowledge is one of the factors that trees will produce hazards to the students and staffs at the campus. Two objectives of this study are (i) to determine the user comfort attributes that significantly influent the safety landscape and (ii) to create the theoretical framework for tree management in campus design. The qualitative method was chosen in this study. This study provides the guidance for the landscape architect to make the right design decision to ensure the user comfortability for safety built landscape environment.
\end{abstract}

Keywords: Theoretical framework; tree management; campus design; comfort

eISSN: 2398-4287@ 2018. The Authors. Published for AMER ABRA cE-Bs by e-International Publishing House, Ltd., UK. This is an open access article under the CC BYNC-ND license (http://creativecommons.org/licenses/by-nc-nd/4.0/. Peer-review under responsibility of AMER (Association of Malaysian Environment-Behaviour Researchers), ABRA (Association of Behavioural Researchers on Asians) and cE-Bs (Centre for Environment-Behaviour Studies), Faculty of Architecture, Planning \& Surveying, Universiti Teknologi MARA, Malaysia.

DOI: https://doi.org/10.21834/e-bpj.v3i7.1284

\subsection{Introduction}

This study purpose the theoretical framework for trees management in campus landscape design. A case study is Universiti Teknologi MARA, (UiTM) campus Shah Alam, Malaysia. With green space in short supply, maintaining a healthy and abundant tree canopy is essential for preserving wildlife habitat, providing shade for buildings and walkways and creating restorative spaces and a sense of place for students, staff and faculty. Variety of trees species contribute to campus identity while playing an important role in preparing the campus for the inevitable impacts of climate change. Selecting a tree that is appropriate for the selected site is critical to ensuring the long-term health of the tree. The factors should be considered during the planting trees are the height of the tree, canopy size, tree form, habitat requirements and impacts of leaf and fruit drop. However, lacking in tree maintenance caused many matured trees is fall and hazards to the public (Avolio et al., 2015). This happens when heavy rain and strong wind. Because of that, students and staffs in this campus feel scared when through the potential of hazardous trees. Good tree management is the key basis for greener campus of the future. Healthy trees on campus will influence the quality of student's life. However, lacking in trees knowledge such as pruning technique is one of the factors that trees will produce hazards to the students, staffs and the properties values at the campus (Kapoor, 2015). Also, the climate change cause the fallen tree occurs suddenly. Trees on campus face a severe limitation of plantable space and an exceptionally stressful growing environment. Indeed, the theoretical framework for trees management developed to be acting as the parameter to evaluate the user comfort and the safety landscape. Thus, this study drives to prevent the future landscape design that less of pay attention to user comfort caused by trees hazardous aspect. Therefore, two objectives of this study are (i) to determine the user comfort attributes that significantly influent the safety landscape and (ii) to create the theoretical framework for tree management in campus design. The qualitative method was chosen in this study whereby five experts respondent in the study area was selected

eISSN: 2398-4287C 2018. The Authors. Published for AMER ABRA cE-Bs by e-International Publishing House, Ltd., UK. This is an open access article under the CC BYNC-ND license (http://creativecommons.org/licenses/by-nc-nd/4.0/). Peer-review under responsibility of AMER (Association of Malaysian Environment-Behaviour Researchers), ABRA (Association of Behavioural Researchers on Asians) and cE-Bs (Centre for Environment-Behaviour Studies), Faculty of Architecture, Planning \& Surveying, Universiti Teknologi MARA, Malaysia.

DOI: https://doi.org/10.21834/e-bpj.v3i7.1284 
based on the experience with hazard trees and agree to share the experiences. Therefore, the Atlas.ti software employed to determine the user comfort factors and attributes that significantly influence with safety landscape.

\subsection{Literature Review}

\subsection{Tree Management}

Tree management is about planning, planting, maintenance, protection and care of trees, forests, green space and related resource for economic, environmental, social and public safety (Jones and Davies, 2017; Bettinger et al., 2016; Wolf and Robbins, 2015; Rafiuddin, 2011). Trees management includes the development of citizen involvement and support for investments in long-term management of tree planting, protection and care programs. Tree management such as conservation and maintenance of hazard trees can be achieved effectively through the development and implementation of strategic tree management (Hong Kong Conservancy Association, 2009). The conservancy proposes the strategy in managing our urban tree resources which are planning and tree selection, tree planting, tree maintenance, tree assessment and risk management and tree protection (figure 1) to make sure the trees in healthy condition.

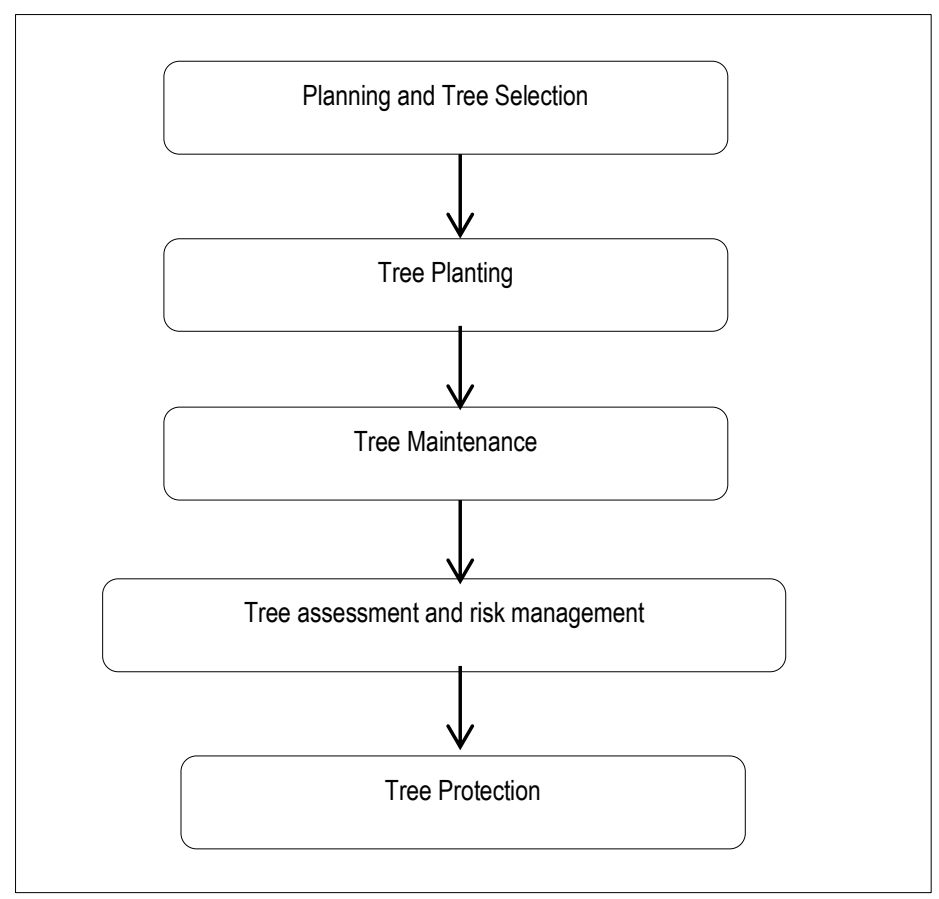

Figure 1: Essential stage of tree management in urban environments

\subsection{Important of Tree Maintenance in Campus Design}

Trees are wonderful to grow in the campus area whether in the courtyard, parking area, along with the walkway and close to the buildings. Trees make the landscape more beautiful and cool the spaces. To maintain the benefits of the trees, people also need to take care of the trees. Proper maintenance required to ensure the tree is healthy and growth well. Maintenance pruning is a way to keep woody plants healthy and productive. The proper maintenance pruning will protect the trees from pests and disease which can gain entry into a plant through dead wood, broken branches and wounds caused by branches that are rubbing together. Also, dead leaves and branches should be removed right way as well as parts that have been infested with insects to maintain healthy growth of the tree branches Tree diseases may be caused by pathogens including fungi, nematodes, bacteria and viruses. Each pathogen is capable of infecting only certain trees. Table 1 showed the types of tree maintenance in the study area.

Table 1: Types of tree maintenance in the study area

\begin{tabular}{ll}
\hline Types of maintenance & Scope of maintenance \\
\hline Pruning & Trim by cutting away dead or overgrown branches especially to encourage growth \\
\hline Tree replacement & The dead tree needs to be replaced with a new tree \\
\hline Pets and disease control & Managing pets and diseases for preventing tree damage and assessing symptoms \\
\hline Fertilizing & A chemical or natural substance added to soil to increase its fertility \\
\hline
\end{tabular}

\subsection{Developments of Theoretical Framework}

The development of theoretical framework based on Kolcaba's comfort theory which highlighted the human comfortable in safe tree condition in the study area. Effect of the hazardous trees such as broken branches, fallen tree and leaning tree trunk are reflecting the comfortable of the students and staffs. In the psychology study, the human comfortable related to the three important attributes such as 
belief, attitude and behaviour as referred to the notaries nursing theory developed by Kolcaba (1994). Based on this theory, researchers develop a theoretical framework and link with the safe tree condition. Meanwhile, previous research also mentioned that different level of knowledge might affects the commitment and action of the receiver (Jylha \& Suvanto, 2015).However, Theory of Dempster-Shafer has been injected to maintenance management showed that human belief as part of the indication information and knowledge of expert's maintenance. The previous study was done by Potes et al., (2013) found that the behaviour expertise and daily attitude practice delivered to the decision of the nature of maintenance management. Indeed, belief seems crucial in maintenance management. Thus, in this development of the theoretical framework, three important part should be considered in comfortable are belief, behaviour and attitude.

\subsubsection{Comfortable}

There are various psychological studies about the feeling of comfort and have resulted in a few conclusions. Comfortable is a sense or psychological ease often characterized as lack of hardship. Persons who are lacking in comfort are experiencing discomfort. The adjective comfortable describes something that makes human feel relaxed. In other words, comfortable means enjoying or providing a position of contentment and security. Related to this study, student and staff should feel free from stress or worry during passing under a matured trees or potentially hazardous trees.

\subsubsection{Attitude}

Attitude is a psychological construct, a mental and emotional entity that inheres in or characterizes a person. Attitude is a favourable or unfavourable evaluative reaction toward something or someone exhibited in one's beliefs, feelings, or intended behaviour. It is a social orientation an underlying inclination to respond to something either favourably or unfavourably. Three components of attitudes are cognitive, affective and behavioural. Cognitive refers to our thoughts, beliefs, and ideas about something. Affective refer to feelings or emotions that something evokes and behavioural refer to tendency or disposition to act in certain ways toward something.

\subsubsection{Belief}

Belief can be defined as the feeling of being certain that something exists or it true.Belief is the state of mind in which a person thinks something to be the case with or without there being empirical evidence to prove that something is the case with factual certainty. In other words, belief is the state of mind in which a person thinks something to be the case with or without there being empirical evidence to prove that something is the case with factual certainly.

\subsubsection{Behaviour}

Behaviour can be defined as the way that someone behaves. In other words, behaviour refers to a psychological approach which emphasizes scientific and objective methods of investigation. The approach is only concerned with observable stimulus-response behaviours and states all behaviours are learned through interaction with the environment.

\subsubsection{Safe trees}

The safe tree can be defined as a tree in health conditions and provide benefits to the human. Tree produce oxygen, intercept airborne particulates, reduce smog and enhancing a community's respiratory health. Also, the tree also provides important habitats for numerous bird and animal species.

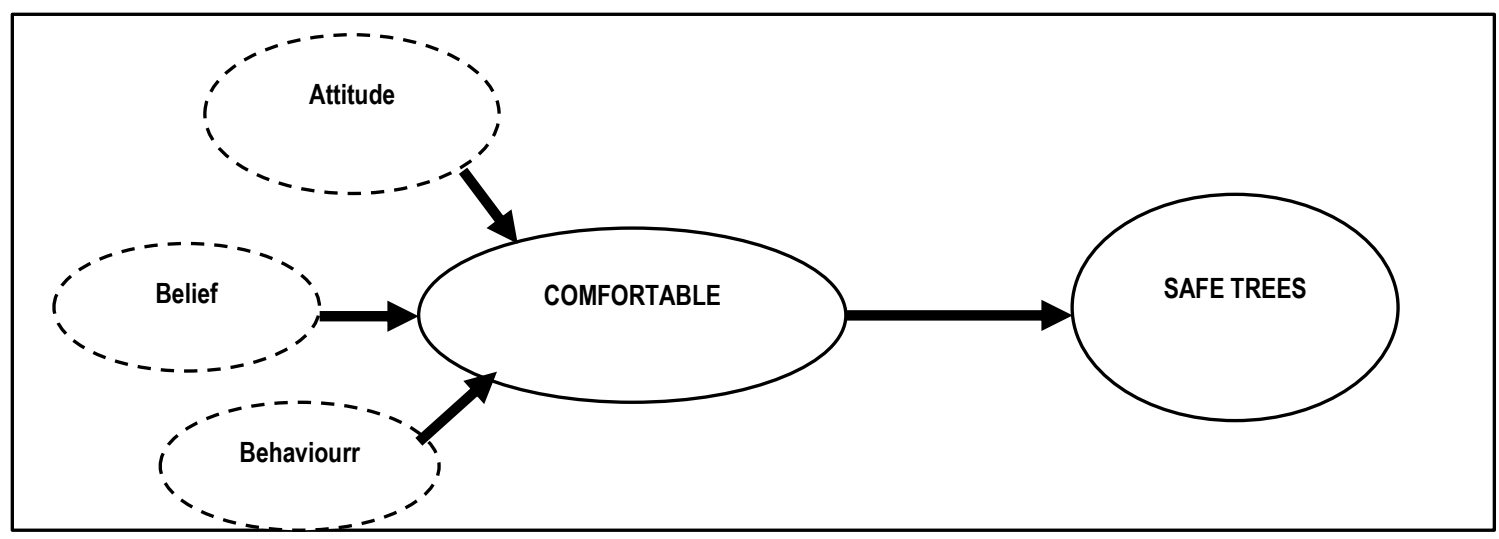

Figure. 2: Development of a theoretical framework for tree management

\subsection{Psychology, well - being and health}

Trees accompany us through life. Relationships between trees and human are complex and have been poorly investigated. The potential of such relationships become clear if human considers the 'campus tree'. Even today, it is uncommon for students or staffs to plant a tree on the campus. Positive feelings towards 'campus tree' are usually associated with aesthetics; 'look nice', 'the blossoms' and 'the colour of the leave'. However, it also associated with comfortable; 'safe trees'; 'shaded area' and 'food source'. Trees are also increasing important for students and staffs health. Campus design may therefore also be called' therapeutic landscape' is currently on the rise. Due to their positive impact on human psyche and health (Cox, 2011; Lee and Maheswaran, 2011) and they have been proven to 
accelerate recovery and regeneration, tree dominates the campus that belongs to hospitals, spas and asylums. The also reduce noise and improve the quality of air and have a calming effect on the mind (Harris et al., 2004; Tyrvainen et al., 2005). Table 2 showed the psychological, physical and social benefits in campus design.

Table 2 showed the psychological, physical and social benefits in campus design.

\begin{tabular}{ll}
\hline Psychological benefits & $\begin{array}{l}\text { Being close to nature brings us closer to our nature } \\
\text { Increased relaxation and well -being } \\
\text { Reduced stress level } \\
\text { Anti-depressant effects of light and greenery }\end{array}$ \\
\hline Physical benefits & $\begin{array}{l}\text { From physical activities (walking to classes, jogging and other exercising) } \\
\text { Increase energy from the cool and fresh air } \\
\text { Stimulation of all the senses } \\
\text { Increased cognitive performance }\end{array}$ \\
\hline Social benefits & $\begin{array}{l}\text { Stimulation of interaction between different cultures } \\
\text { Increasing feeling of belonging reduced social isolation } \\
\text { Increased sense of responsibility due to consideration of natural interrelations. }\end{array}$ \\
\hline
\end{tabular}

\subsection{Case Study}

\section{Faculty of Architecture, Planning and Surveying}

The justification of the selection case study is because the faculty which has long been established in Universiti Teknologi MARA. This faculty also has a variety of matured tree species such as Plumeria rubra (Kemboja merah), Ficus benjamina (Beringin), Maniltoa brawneodes (Handkerchief tree), Pelthophorum pterocarpum (Batai laut) and variety of fruit trees. This faculty located at Shah Alam and within the Klang Valley, the faculty has gained its reputation as one of the pioneering institutions which offered courses in the field of the built environment. The faculty was established in July 1967 with an initial enrolment of 60 students under what was known as the School of Applied Arts, which was later changed to the School of Arts and Architecture. In 1971 the School of Arts and Architecture had undergone a major reorganization, and this led to the establishment of two separate schools; one, which emphasized on the built environment, and the other on the arts and design. Subsequently, the built environment school was named as the School of Architecture, Planning and Surveying which was later known as the Faculty of Architecture, Planning and Surveying.

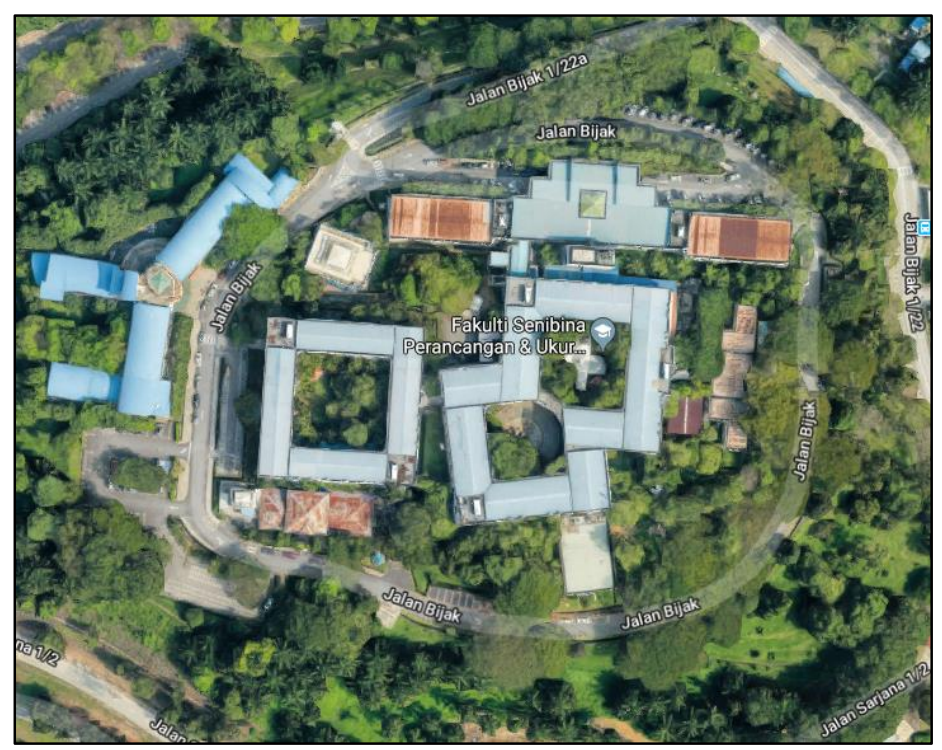

Figure1.1 View towards Faculty of Architecture, Planning and Surveying (Source: Google map)

\subsection{Methodology}

\subsection{Qualitative approach}

Qualitative Research is primarily exploratory research. It is used to gain an understanding of underlying reasons, opinions, and motivations. Qualitative data collection methods vary using unstructured or semi-structured techniques. Some common methods include focus groups (group discussions), individual interviews, and participation/observations. The sample size is typically small, and respondents are selected to fulfil a given quota. As explained by Kumar (2011), the exploratory study is scientific research due to the knowledge of the research area. This study used ethnography methods to deliver the exploratory to achieve and completed the data 
information by the experts. Thus, the in-depth interviews with five landscape architects focus on experience and knowledge of the tree condition in the study area. In an attempt to make the interviewee feel as comfortable as possible, prepared ourselves with the high degree of thematic competence on the part of interviewer before conduct the ethnography study (Pfadenhauer, 2009). The face to face interview, a piece of paper contained the list of all elements in a variable included together in the instrument presented onto the interviewee table. The experts also acted as the judge of the upcoming content validity for explanatory phase. The interview began with filling their demography information by themselves. To answer the research question, the central question asked in the interview. The experts responded to the question, and the audio was recorded using a voice recorder in MP3 version format. After data collection next is to process the data obtained following the techniques proposed by Meuser and Nagel (2009). (Refer figure 3)

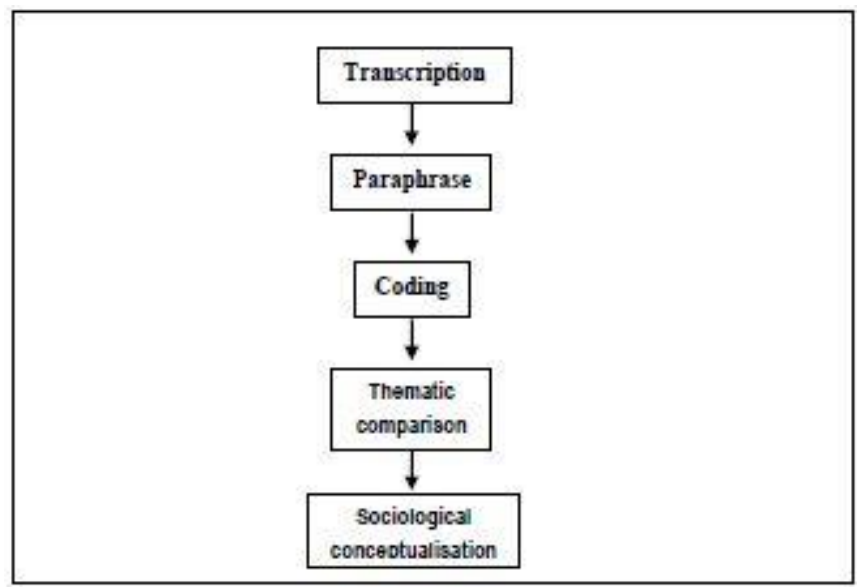

Figure 3 Technique of data collection in this study

\subsection{Instrument}

The semi-structured instrument consisted of open-ended question avoid the potential risk of data collection interruption. The instrument also consisted the written space need to be administrative by experts regarding their basic demographic included in the instrument.

\subsection{Respective sample}

In the scientific research, an individual addressed to be an expert due to researcher judgment for the certain reason that namely interpretative knowledge, technical knowledge and process knowledge (Bogner, Littig, \& Menz, 2009). Thus, in the selection of experts in this ethnography study and selected of the respondents are five people in landscape architecture that knowledgeable in research.

\subsection{Using thematic analysis in ATLAS.ti Software}

These research using thematic analysis to generate the data analysis. The purposes of the software adoption in this qualitative study are to indexing the data collected in a desired way and retrieval of data with a fast search speed. It is important to the researcher to select best the appropriate computer programme to analyse the data. The researchers choose the Atlas.ti software among the qualitative analysis programme proposed for certain reasons. Atlas.ti belongs to the genre of Computer-Aided Qualitative Data Analysis (CAQDAS) programme. CAQDAS also increases the validity of research results, particularly in the conceptual data analysis than the manual that easy to 'forget' the raw data behind (Friese, 2014).

\subsection{Findings and Discussion}

From the in-depth interviews with five experts from the landscape practices to get their perception of the comfortable towards the safety trees in the study area, three among of them were landscape practitioner while two of them were academicians. The respondents have registered landscape architecture with Institute of Landscape Architecture Malaysia (ILAM) and have experience and knowledge on the existing tree in the study area. From the interview results, the data of the interviews are recorded using MP3 audio and transferred to the Hermeneutic Unit (HU) in ATLAS.Ti 7.5 software for transcription the document. Next is created an embedded document in Hermeneutic Unit to generate the transcription of each recorded data. The ordinary units in the transcription are paraphrased. After that, the relevant information is highlighted and quoted in the code for the specified theme at the stage of thematic analysis. Each theme represented by the code in the analysis. Every element structured is associated with main code (Attitude, Belief, Behaviour and Safety Trees). Every sub-code of the particular sentences known as a quotation that related to codes highlighted to link with the main code. Moreover, the function of MEMO is to support the point of view of any arguments. Therefore, figure 4.1 shows the final network mapping of the framework development of the relationship of comfortably and safety trees arranged by Atlas.ti Software. Figure 4 showed the framework development between comfortable and safety trees in the study area. 


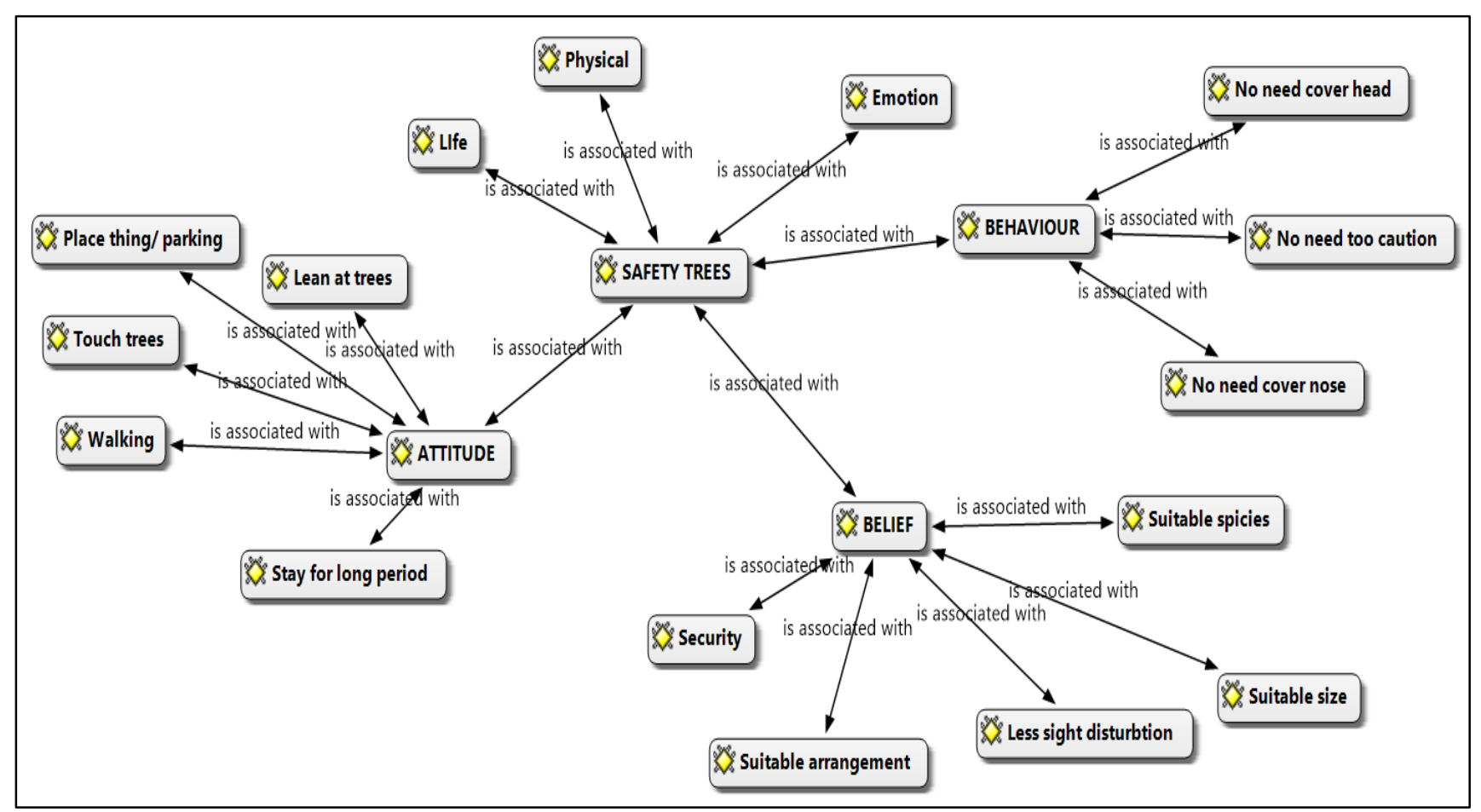

Figure 4: Framework Developments of the Relationship of Comfortable and Safe Trees

\subsection{Main Code: Theme of Safety Trees}

\section{a) Sub-code: Life}

The 'life' theme quoted all the five interviewees. The 'life' theme considered as crucial as the parameter. Researchers notified that all interviewees believed that the human life considered included in life quotation. Only interviewees two and five are attached to the memo and mentioned about animal's life. Thus, life theme reflected human and any appropriate macro-organism and the safety trees.

\section{b) Sub-code: Physical}

The quoted of 'physical' theme quoted all the five interviewees. Therefore, researchers included physical in the safety parameter.

\section{c) Sub-code: Emotion}

Among five interviewees, the theme 'emotion' only quoted in interviewee three in the natural unit. The consisted natural unit is: .... surprisingly, sometimes, the physical trees itself or the malfunction of trees by nonsense spiritual activities caused funny taboo or rumours, this situation like creating the unpleasant user's emotion_environment. For instance, ghost or spiritual appearance...

The quoted quote above reflected the wrong selection of trees spices might bring sometimes creating the unpleasant emotion due to the local society mind set. Thus, researchers agreed with respondent's opinions and included emotion in safety parameter.

\subsection{Main Code: Attitude Theme}

The quoted of 'attitude' theme in all interviewees at the natural unit. Table 4 showed two quotations in 'walking' are coded (interviewee 1 and 3). Four quotations in 'touch trees' are coded (except interviewee 3). Meanwhile, five quotations in 'place thing/ parking' are coded, and three quotations in 'leaning trees' are coded (interviewee 3, 4 and 5).

\subsection{Main Code: Belief}

The quoted of 'belief' theme in all interviewees at the natural unit. Table 4 indicated that two quotations quoted in 'suitable size' are coded (interviewee 4 and 5), three quotations quoted in 'less sight disturb' are coded (interviewee 2, 4 and 5), two quotations quoted in 'suitable arrangement' are coded (interviewee 2 and 3), three quotations quoted in 'security' are coded (interviewee 3, 4 and 5) and three quotations quoted in 'stay for long period' are coded (interviewee 1, 2 and 4).

\subsection{Main code: Behaviour}

The quoted of 'behaviour' theme in interviewee 3 and four at the natural unit. The table 4 elaborated that only 'no need cover head' are coded (interviewee 4). Meanwhile, respondents' five quotes 'no need acted too caution' code and quoted two quotes 'no need cover nose' code (interviewee 2 and 4). 
In a nutshell, the analyzed of interview data confirmed that Belief, Attitude and Behavior in comfortable in parameter and influence with the safety trees. The interview also came out with 12 elements in comfortably variable.

Table 4.The Summarized Elements Consisted in Each Attitude, Belief and Behavior Constructs: Manual Arranged from Data in Network Mapping that We Quoted from Hermeneutic Unit (HU)

\begin{tabular}{|l|l|c|c|c|c|c|}
\hline Main Code & Sub-code & $\mathbf{1}$ & $\mathbf{2}$ & $\mathbf{3}$ & $\mathbf{4}$ & $\mathbf{5}$ \\
\hline Behaviour & No need cover head & & & & $/$ & \\
\hline & No need acted too caution & $/$ & $/$ & $/$ & $/$ & $/$ \\
\hline & No need cover nose & & $/$ & & $/$ & \\
\hline Belief & Suitable size & & & $/$ & & $/$ \\
\hline & Less sight disturb & & $/$ & & $/$ & $/$ \\
\hline & Suitable arrangement & & $/$ & $/$ & & \\
\hline & Security & & & $/$ & $/$ & $/$ \\
\hline & Stay for long period & $/$ & $/$ & & $/$ & \\
\hline Attitude & Walking & $/$ & & $/$ & & \\
\hline & Touch trees & $/$ & $/$ & & $/$ & $/$ \\
\hline & Place thing/ parking & $/$ & $/$ & $/$ & $/$ & $/$ \\
\hline & Leaning trees & & & $/$ & $/$ & $/$ \\
\hline
\end{tabular}

\subsection{Conclusion}

The feeling of unsafety tree for either physical or environmental impacted the user discomfort. Indeed, the theoretical frameworks for tree management are developed to be acting as the parameter to evaluate the students and staffs comfort and the safety landscape. Thus, this study drives to prevent the future landscape design that less of pay attention to user comfort caused by hazardous trees aspect. Therefore, the primary objective of this study is to determine the user comfort attributes that significantly influent the safety landscape. The qualitative methods choose in this study whereby five landscape practices and experts in the research area. Thus, the Atlas.ti software employed to determine the user comfort factors and attributes that significantly influence safety landscape. This study revealed that three user comforts attributes in need to reach the safety landscape namely, belief, attitude and behaviour. This study provides the guidance for the landscape architect to make the right design decision to ensure the user comfortably for safety built landscape environment.

\section{Acknowledgements}

The authors would like to extend the utmost appreciation to the respondents for their exceptional dedication and enthusiasm and for sharing their valuable time and support. This appreciation also goes staffs and lecturers from Faculty of Architecture, Planning and Surveying, Universiti Teknologi MARA, Shah Alam, Selangor, Malaysia for the expertise and financial support. The authors also acknowledge the constructive comments for reviewing the manuscript.

\section{References}

Avolio, M. L., Pataki, D. E., Pincetl, S., Gillespie, T. W., Jenerette, G. D., \& McCarthy, H. R. (2015). Understanding preferences for tree attributes: the relative effects of socio-economic and local environmental factors. Urban ecosystems, 18(1), 73-86.

Bogner, A., Littig, B., \& Menz, W. (2009). Introduction: Expert Interviews - An Introduction to a New Methodological Debate. In B. Kittel, C. von Ossietzky, \& B. Rihoux (Eds.), Interviewing expert (pp. 1-16). United Kingdom: Palgrave Macmillan.

Cox,S. (2011). Urban tree-a practical management guide.Crowood Press, Cambridge.

Friese, S. (2014). Qualitative Data Analysis with ATLAS. Ti (Second edi). USA: Sage Publications.

Hegazy, T., Ahluwalia, S. S., \& Attalla, M. (2010). Two Condition Indicators for Building Components Based on Reactive-Maintenance Data. Journal of Facilities Management, 8(1), 64-74. http://doi.org/10.1108/14725961011019085

Hsieh, H.-F., \& Shannon, S. E. (2005). Three Approaches to Qualitative Content Analysis. Qualitative Health Research, 15(9), 1277-1288. http://doi.org/10.1177/1049732305276687

Harris, R.W., Clark, J.R. and Matheny, N.P. (2014). Arboriculture, Fourth Edition Pearson Education ,Prentice Hall, New Jersey.

Jylha, T., \& Suvanto, M. E. (2015). Impacts of Poor Quality of Information in The Facility Management Field. Facilities, 33(5/6), 302-319. http://doi.org/10.1108/F-072013-0057

Kolcaba, K. (1994). A Theory of holistic comfort for Nursing. Journal of Advance Nursing , (Vol. 19, (6), pp. 1178-1184)

Kumar, R. (2011). Research Methodology: A Step-by-step guide for beginners (3rd Edition) (3rd Editio). London: SAGE Publications.

Kapoor, P., Rani, R., \& JMIT, R. (2015). Efficient Decision Tree Algorithm Using J48 and Reduced Error Pruning. International Journal of Engineering Research and 
General Science, 3(3).

Lee, A. and Maheswaran, R. (2011). The health benefits of urban green space: Areview of the evidence.Journal of Public Health 33 (2), 212 - 222

Meuser, M., \& Nagel, U. (2009). The Expert Interview and Changes in Knowledge Production. In B. Kittel, C. von Ossietzky, \& B. Rihoux (Eds.), Interviewing expert (pp. 17-42). United Kingdom: Palgrave Macmillan.

Othman, N., \& Mat, M. (2015). Street Planting Compositions : The Public and Expert Perspectives. In AcE-Bs2014Seoul Asian Conference on Environment-Behaviour Studies Chung-Ang University, Seoul, S. Korea, 25-27 August 2014 (Vol. 170, pp. 350-358). http://doi.org/10.1016/j.sbspro.2015.01.045

Pfadenhauer, M. (2009). At Eye Level: The Expert Interview - a Talk between Expert and Quasi-expert. In B. Kittel, C. von Ossietzky, \& B. Rihoux (Eds.), Interviewing expert (pp. 81-97). United Kingdom: Palgrave Macmillan.

Potes Ruiz, P. A., Kamsu-Foguem, B., \& Noyes, D. (2013). Knowledge Reuse Integrating the Collaboration from Experts in Industrial Maintenance Management. Knowledge-Based Systems, 50, 171-186. http://doi.org/10.1016/j.knosys.2013.06.005

Sekaran, U., \& Bougie, R. (2013). Research Method for Business: A Skill-Building Approach (Sixth edit). United Kingdom, England: John Wiley \& Son.

Too, E. (2012). Infrastructure Asset: Developing Maintenance Management Capability. Facilities, 30(5/6), 234-253. http://doi.org/10.1108/02632771211208503 